\title{
Françoise Van Rossum-Guyon, Balzac: la Littérature réfléchie. Discours et autoreprésentations
}

\section{Marco Stupazzoni}

\section{(2) OpenEdition}

1 Journals

\section{Edizione digitale}

URL: https://journals.openedition.org/studifrancesi/40902

DOI: 10.4000/studifrancesi.40902

ISSN: 2421-5856

\section{Editore}

Rosenberg \& Sellier

\section{Edizione cartacea}

Data di pubblicazione: 1 juillet 2004

Paginazione: 207-208

ISSN: 0039-2944

\section{Notizia bibliografica digitale}

Marco Stupazzoni, «Françoise Van Rossum-Guyon, Balzac: la Littérature réfléchie. Discours et autoreprésentations», Studi Francesi [Online], 142 (XLVIII | I) | 2004, online dal 30 novembre 2015, consultato il 09 septembre 2021. URL: http://journals.openedition.org/studifrancesi/40902 ; DOI: https://doi.org/10.4000/studifrancesi.40902

Questo documento è stato generato automaticamente il 9 septembre 2021.

\section{(c) $(1) \ominus$}

Studi Francesi è distribuita con Licenza Creative Commons Attribuzione - Non commerciale - Non opere derivate 4.0 Internazionale. 


\title{
Françoise Van Rossum-Guyon, Balzac: la Littérature réfléchie. Discours et autoreprésentations
}

\author{
Marco Stupazzoni
}

\section{NOTIZIA}

FRANÇOISE VAN ROSSUM-GUYON, Balzac: la Littérature réfléchie. Discours et autoreprésentations, Université de Montréal, Département d'Études françaises, 2002 («Paragraphes»), pp. 203.

1 Le riflessioni condotte in questa interessante pubblicazione da F. van Rossum-Guyon colgono l'importanza e la modernità della Comédie humaine balzachiana nel fatto che essa costituisce un vero e proprio laboratorio in cui lo scrittore si interroga sui maggiori problemi legati alla rappresentazione e alla comunicazione letterarie.

Il volume, inaugurato da una penetrante introduzione di Stéphane vaCHON (Avantpropos, pp. IX-XIX) si struttura in due parti fondamentali, di cui la seconda è centrata, in modo particolare, sull'analisi di Illusions perdues.

3 Il metadiscorso assume, in Balzac, un rilievo particolare e al limite del paradosso, se lo si guarda come discorso autonomo perfettamente isolabile dal contesto narrativo; tuttavia, osserva l'A., esso "découpe, organise et rationalise son langage-objet» esibendone «les modèles de fonctionnement ainsi que les codes de référence à partir desquels il se construit tout en soulignant les conditions de possibilité de sa lecture» (p. 19). In questo senso, la valenza polifunzionale della digressione sull'argot in Splendeurs et misères des courtisanes riveste un valore simbolico particolarmente evidente in quanto esso "prête ses pouvoirs et, en particulier, son 'affreuse poésie' aux 'scènes curieuses annoncées par le narrateur» (p. 27). La specificità del metadiscorso balzachiano nel Cousin Pons e nella Cousine Bette è colta dall'A. grazie ad un suggestivo inventario degli interventi metanarrativi nei due romanzi considerati, mentre, per quel 
che riguarda Le Père Goriot, è assunto come punto di vista privilegiato l'analisi del discorso di Vautrin a Rastignac, all'interno del quale la portata delle dinamiche e degli effetti prodotti dal discorso autoriale mostra «à la fois les desseins des locuteurs et les effets de leurs paroles sur leurs allocutaires» (p. 62). Il ruolo della digressione in relazione alla funzione rappresentativa della descrizione del personaggio in Béatrix $\mathrm{e}$ nel Curé de village rappresenta una traccia importante, dal punto di vista enunciativo, del rilievo attribuito da Balzac al discorso come azione e come parte integrante, o, per meglio dire, determinante della struttura del racconto.

4 Da questo punto di vista, il caso di Illusions perdues è quanto mai esemplare: l'opera può essere considerata come un immenso enunciato metaletterario, da cui si riflette un nuovo sapere sulla letteratura: «ce sont, en effet, les transformations que la progression fait subir aux figures et aux situations, qui permettent de situer Illusions perdues comme roman moderne et chef-d'oeuvre du genre de l'ensemble des productions dont il est question dans la fiction» (p. 120). La rappresentazione della letteratura in tutti i suoi aspetti si compie grazie ai dialoghi e ai discorsi relativi ai personaggi stessi della storia: in questo senso, «la mise à nu des systèmes de valeurs propres aux différents acteurs et à chaque instance, y compris celle du narrateur, qui n'est qu'une des voix du roman, montre combien le texte balzacien est ambivalent et suscite par conséquent le conflit des interprétations» (p. 178). 